\title{
FRAGMENTOS (AUTO)BIOGRÁFICOS: EDUARDO FRIEIRO NA SUA CORRESPONDÊNCIA
}

Maria da Conceição Carvalho

Pós-Lit/UFMG

\begin{abstract}
RESUMO
Perfil do escritor Eduardo Frieiro (1889-1982), homem introvertido e dado à autoanálise, delineado por ele mesmo nas cartas que enviou a intelectuais do seu tempo. O exame desse corpus epistolar permitiu identificar um autorretrato, fragmentado e recorrente, que o pesquisador redesenha na forma de um ensaio biográfico.
\end{abstract}

\section{PALAVRAS-CHAVE}

Eduardo Frieiro, correspondência, autobiografia, biografia

Que mejor modelo de autobiografia se puede concebir que el conjunto de cartas que uno há escrito y enviado a destinatarios diversos, mujeres, parientes, viejos amigos, en situaciones y estados de ánimo distintos?

Ricardo Piglia. Respiración artificial.

No espaço dos Estudos Literários tem havido, nas últimas décadas, um retorno à figura do autor, no rastro da crítica genética, que, ao buscar a origem do texto e de todo o processo de seu desenvolvimento, volta-se necessariamente para a vida do escritor, seu ambiente de trabalho e o percurso do seu pensamento crítico. Daí a revalorização da pesquisa em arquivos literários, sobressaindo-se, entre muitos tipos de documentos ali depositados, a correspondência pessoal como fonte primária extremamente rica de possibilidades informacionais sobre os embates cotidianos do escritor com a cultura do seu tempo e seu processo de criação. De fato, tomada como modalidade da chamada escrita de si, a carta pessoal, geralmente estudada em séries, vem merecendo renovada atenção de pesquisadores de diferentes campos como fonte e, mais raramente, como objeto mesmo de pesquisa. De modo especial as cartas trocadas entre intelectuais, 
prática de sociabilidade comum até os meados do século 20, revelam pactos literário/intelectuais, tramas de poder e o jogo político de um cenário específico no qual se interpenetram as esferas pública e privada, podendo ser vistas, igualmente, como um espaço paradoxal, ${ }^{1}$ zona enigmática entre a vida e o texto, onde é possível falar de si mantendo-se, a uma distância segura, o interlocutor.

\section{A CORRESPONDÊNCIA COMO ATO AUTOBIOGRÁFICO}

Tendo como objetivo lançar alguma luz sobre a figura do escritor Eduardo Frieiro (1889-1982), algo esquecido no último quarto de século que se seguiu à sua morte, a fonte principal desse ensaio foi, pois, a correspondência ativa do escritor, partindo-se da suposição de que o homem tímido e reservado que se autonomeia Um Robinson das Letras ${ }^{2}$ utiliza-se da interlocução epistolar para edificar sua autoimagem de intelectual, tal como ele quer vê-la preservada após sua passagem. Pensamos como Foucault, em A escrita de $\mathrm{si}^{3}$ que escrever uma carta é um movimento coordenado de lançar um olhar ao destinatário e, ao mesmo tempo, dar-se ao seu olhar. A particularidade da escrita epistolar está, pois, em que, sendo um texto destinado à interlocução com o destinatário, é também (ou pode ser) um espaço especial para o exercício de autoconhecimento de quem escreve. Se aceitarmos a crença da psicanálise de que falando e escrevendo (grifo nosso) o sujeito se produz, literalmente, apoiando-se na palavra como forma de constituição do $\operatorname{ser}^{4}$ podemos entender o intercâmbio epistolar como um jogo relacional no qual, ao narrar-se, o remetente vai constituindo uma imagem de si para si mesmo, como vai, também, dando-se ao conhecimento do outro, o destinatário da carta. Quanto a este, deixa de ser figurante passivo para ser visto como motor e coresponsável pela natureza do que será revelado pelo autor da missiva. Nesse sentido, as contradições que eventualmente aparecem ao longo da correspondência de uma mesma pessoa, de uma carta para outra, (e o retrato que Frieiro faz de si na sua correspondência é multifacetado e cambiante), sugerem que o remetente epistolar assume diferentes máscaras, diante de diferentes interlocutores, tomados esses como mediadores para o encontro consigo mesmo. Assim, menos importante do que

\footnotetext{
${ }^{1}$ Kaufmann citado por TREBITSCH. Correspondences d'intellectuels.

${ }^{2}$ FRIEIRO. Um Robinson Literário.

${ }^{3}$ FOUCAULT. L'écriture de soi, p.149-50

${ }^{4}$ CALLIGARIS. Verdades de autobiografias e diários íntimos.
} 
averiguar a verdade contida na narração de fatos passados é pensar porque o sujeito que escreve sobre si escolheu relembrar uma versão particular do passado e, principalmente, o que isso significa para ele naquele momento. Sem ser uma autobiografia stricto sensu a correspondência abriga lapsos memorialísticos, reflexões e sentimentos pessoais, enfim, os movimentos interiores de quem escreve. Em outras palavras, no extenso quadro gradativo ocupado pelos textos autobiográficos, "que vai da insipidez do curriculum vitae à complexa elaboração formal da pura poesia”, 5 poderíamos nomear a correspondência como ato autobiográfico, situado a meio caminho entre a formalidade do primeiro e a liberdade de criação inerente à poesia. No espaço da carta como ato autobiográfico intencionado o sujeito postula, para poder narrar sua história, uma relação de semelhança entre o eu que viveu e o que hoje escreve propondo ao seu leitor um pacto autobiográfico, ${ }^{6}$ ou seja, assumindo o compromisso de contar sua vida, ainda que em partes, dentro de um espírito de verdade. Mas, paradoxalmente, permitindo-se devaneios, ou autointerpretações, na expressão de Starobinski (1970). Frieiro, ele próprio, confessa essa liberdade dos textos autobiográficos em carta a Nelson Lustosa Cabral, de 3 de novembro de 1963: "Dizia Renan, nos Souvenirs d'enfance que tudo o que cada um diz de si é sempre poesia. Escrevem-se 'souvenirs' para transmitir a outros a teoria do universo que cada um traz consigo." Pois bem, estimulados pela possibilidade de desvendar as relações entre a escrita epistolar e a escrita de si e, ao mesmo tempo, de compreender o processo de autorrepresentação de Frieiro através de sua correspondência, resgatamos fragmentos de cartas suas, seguindo uma linha temporal contraposta ao ritmo descontínuo e repetitivo de suas reflexões que resultou numa espécie de autobiografia dentro de uma biografia.

Como outros intelectuais do seu tempo, e anteriores a ele, Eduardo Frieiro desenvolveu ao longo de sua vida uma rede epistolar significativa e, além de colecionar as cartas recebidas, prática comum entre os missivistas contumazes, guardava também, ordenadamente, as cópias das cartas que enviava. O próprio ritual do arquivamento das cópias, após postados os originais, e as correções e alterações inseridas nessas mesmas cópias em datas posteriores, sugerem que o escritor mineiro não fazia, propriamente, confidencias a um interlocutor escolhido. Na verdade, procurava edificar uma imagem

\footnotetext{
${ }^{5}$ LEJEUNE. Le pacte autobiographique.

${ }^{6}$ LEJEUNE. Le pacte autobiographique.
} 
pública de si, para um público mais vasto, quando (e se) sua correspondência fosse publicada.

Assim, na medida em que nos aprofundávamos na leitura das mais de seiscentas cópias de cartas enviadas a mais de trezentos interlocutores (intelectuais brasileiros e latino-americanos, em sua maior parte), fazia-se notar, cada vez mais nitidamente, o esforço de afirmação identitária presente naquela forma de comunicação. O trabalho de reconstrução de si em formato epistolar, no caso de Frieiro um texto repleto de reiterações e contradições, confirma o dito de Calligaris (1998) sobre o ato autobiográfico, passo sempre crucial na tentativa do sujeito de atribuir a si próprio um significado, de se reconhecer na figura que emerge daquela operação memorialística.

\section{EDUARDO FRIEIRO, ESBOÇO DE PERFIL (AUTO)BIOGRÁFICO}

Autodenominando-se homem livresco, ${ }^{7}$ Frieiro, como tantos outros intelectuais, parece ter orientado sua existência para duas funções fundamentais: ler e escrever. Onde nasceu, como transcorreram seus primeiros anos, as impressões de menino são fatos que merecem pouco espaço no exercício rememorativo do escritor adulto. É como se ele não tivesse existido, de fato, senão a partir de seu nascimento como leitor. Da infância pobre de um filho de imigrantes espanhóis, não são muitos os fatos lembrados nas cartas. Quando afloram, as menções à infância e à juventude vêm, em geral, como autobiografemas no sentido barthesiano, fragmentos de memória, pequenos fatos narrados em descontínuo, quase sempre envolvidos pelo sentimento melancólico e amargo do adulto. Aos 75 anos, escrevendo em 29 de dezembro de 1964 à jovem escritora Ruth Nielsen, com quem manteve um agradável diálogo por vários anos, retrata num matiz sombrio, com poucas pinceladas, as primeiras décadas de sua vida:

Não há na minha vida particular e pública nada que ofereça qualquer interesse biográfico, vida paupérrima em acontecimentos anedóticos. (...) Não me deixaram a mínima saudade, nem a infância nem a juventude. Pelo contrário, nem gosto de as lembrar.

Foi um autodidata quase absoluto. Dois anos e meio do chamado Curso Primário foi o tempo de estudo do menino Eduardo, dos 9 aos 12 anos. Logo seria requisitado para o mundo do trabalho, num meio familiar em que não cabiam "bocas

\footnotetext{
${ }^{7}$ FRIEIRO. Novo diário, p. 40.
} 
improdutivas”. 8 Mas, teria começado ali, na sala de aula de uma escola pública do bairro Carlos Prates, reduto de imigrantes semianalfabetos naquela virada de século, a experiência mais significativa de sua vida: a leitura. A impressão que ele quer passar nas suas rememorações de infância é que sua vida pessoal começa, de fato, no momento em que, lendo, inicia o diálogo com o mundo da representação literária. Contou, certa vez, ao escritor Vivaldi Moreira ${ }^{9}$ que, sendo ele bem novo, via os meninos do bairro furtando amendoim de um velho dono de armazém, que vivia cochilando atrás do balcão. Quanto a ele...

Que ia eu roubar, meu caro Vivaldi? Jornais, jornais velhos, Jornal do Brasil, com a magnífica colaboração; Jornal do Comércio, com artigos quilométricos, e eu bebia tudo aquilo! (...) Fui um grande ledor de jornais! Então, jornal do interior, que delícia! Eu lia, por exemplo: Gazeta de Guaratinguetá, que mistério para mim! Que encanto! Eu lia tudo, tudo.

Fantasiosa ou não, a veracidade dessa história interessa menos ao biógrafo do que a constatação de quão importante para o escritor é repassar para seu interlocutor a idéia de que a leitura foi essa paixão precoce que confere sentido a toda a sua vida, abrindo-lhe um caminho diferente do que lhe seria destinado por tradição familiar. Lembrar o vivido, para Frieiro, é refazer um caminho de textos lidos. É desta maneira que ele resume a sua vida a Euryalo Cannabrava, que pretendia escrever-lhe a biografia, em carta de 2 de fevereiro de 1978:

Aos dez anos eu lia vidas de santos e queria ser santinho. Aos doze anos confessei-me com um padre ignorante. Daí em diante fui perdendo aos poucos a religião. Na adolescência dois amigos espíritas me davam para ler jornaes e livros dessa doutrina. Mas não me convenci. Daí em diante li autores heréticos que muito me seduziam. Li então o meu mestre de ateísmo, Félix Le Dantec, cujas obras apareciam então traduzidas ao português. Peguei uma reta nessa corrente de idéias. Li os materialistas da revolução franceza, Diderot à frente e outros. Era um leitor desabusado, ávido de críticas destruidoras. Li todo o Maupassant, todo Anatole France, todo Rémy de Gourmont, os escritores da Nouvelle Revue Française, o diabo! Fui empolgado pelo anti-cristão Nietzsche. Os escritores espanhóis da geração de 98 me conquistaram. Com Azorín, estilista sem par, apurei a minha arte de escrever. Fui leitor do meu casmurro romancista Pio Baroja. A guerra de Franco mergulhou os espanhóis numa espécie de idade média dominada pelo clero. Fiquei só com os franceses, até Albert Camus e Jean-Paul Sartre, meus últimos oráculos. Com Sartre,

\footnotetext{
${ }^{8}$ FRIEIRO. Novo diário, p. 40.

${ }^{9}$ MOREIRA. Glossário das Gerais, p. 26.
} 
terminou a minha carreira, tranqüila, sem sobressaltos de indivíduo sem as ilusões dos comuns homens religiosos.

Mas, se a leitura foi um desejo concretizado desde muito cedo, a vontade de escrever chegou tarde e desconfiada. Ele conta:

(...) No jornal [Minas Gerais] eu trabalhava como revisor e tinha o dia livre. O trabalho de revisão, penoso para outros, era para mim uma brincadeira. Levava livros que eu lia nos intervalos do trabalho. E tinha o dia todo para ler. Foi então que eu senti comichões para escrever. (...) Tentei-o, pela primeira vez, escrevendo quatro ou cinco artigos para a imprensa e algumas picuinhas anônimas num jornaleco. ${ }^{10}$

O “jornaleco” era o Avante!, publicado em Belo Horizonte pelo Dr. Amadeu Teixeira, e o artigo intitulado “Brotoeja literária”, publicado no dia 20 de agosto de 1925 sob o pseudônimo de João Cotó, causou celeuma no pequeno espaço cultural da cidade pela crítica mordaz aos modernistas mineiros que acabavam de publicar o primeiro número de A Revista. Esse e outros pequenos artigos publicados anonimamente em jornais de São Paulo teriam representado um gesto de afirmação do jovem solitário e ressentido com sua posição social de imigrante pobre, mas que já havia acumulado, então, um extraordinário capital cultural bebido em Montaigne, Voltaire, La Rochefoucauld, Eça de Queiroz, Machado de Assis e outros autores a quem ele credita sua formação intelectual. Pode-se supor que, aliviado com o primeiro jorro escritural, ele se sente com coragem para um empreendimento maior, o livro. Ele escreve a Ruth Nielsen em 6 de fevereiro de 1967:

Publiquei meu primeiro livro [O clube dos grafômanos, 1927] à minha própria custa, quase em segredo e com surpresa das pessoas que me conheciam, que ademais não suspeitavam em mim quaisquer veleidades literárias, embora me soubessem leitor infatigável e de boa formação letrada. O livro foi bem recebido pela crítica e eu continuei a publicar livros, porque só o livro, verdadeiramente, me interessava.

Dito de outra maneira, a publicação de seu primeiro romance, ${ }^{11}$ quando já passava dos 30 anos, parece marcar o momento em que seu espírito crítico, não cabendo mais no espaço do leitor contumaz e do redator de pequenos artigos em jornais de circulação diminuta, transborda para o lugar do scriptor, assumindo-se plenamente

${ }^{10}$ Fragmento de texto manuscrito, sem data e sem destinatário, guardado entre as cartas recebidas. Trata-se, muito provavelmente, de rascunho de carta a ser enviada, em processo de escrita.

${ }^{11}$ FRIEIRO. O clube dos grafômanos. 
como sujeito da enunciação. De fato, bem acolhido pela crítica, logo ele ocuparia um lugar na República das Letras brasileira como escritor lúcido e de estilo apurado que continuaria a construir, até o final da vida, uma obra respeitável como romancista, ensaísta e crítico literário.

Mas, esse escritor polígrafo, como se dizia no seu tempo, carregava consigo um permanente questionamento sobre o sentido da atividade de escritor, dúvida pontuada na sua correspondência ativa de cinco décadas e sistematizada no ensaio A ilusão literária (1932). Com Gualter Gontijo Maciel, por exemplo, em carta de 14 de janeiro de 1960, ele considera:

Há tempos, um repórter literário do Diário da Tarde perguntou-me qual a minha vocação mais pronunciada - a de romancista ou a de crítico? Tive vontade de dizer: a de romancista, mas pensei melhor e respondi: - Nem uma nem outra. Eis o que sou, ou suponho ser: um moralista, antes de nada. Um moralista que abandonou há muito a ética religiosa, um criticón (ao modo de Gracián) que observa os costumes e desejaria, sem esperanças, menos ruindade nos homens.

Embora Frieiro tenha ambicionado, pelo menos no início de sua vida de escritor, fosse o romance a sua vocação maior, conhecedores de sua produção intelectual pensam que é a sua criação ensaística que merece maior destaque. De fato, seus ensaios sobre temas históricos mineiros - O Diabo na livraria do Cônego (1945), Como era Gonzaga? (1950), Feijão, angu e couve (1966) - estão entre seus escritos mais valorizados pelos críticos e também mais conhecidos pelo público leitor. Embora afirmasse, repetidamente, não ser um historiador, Frieiro integra, como estudioso da História, o rol dos explicadores do Brasil, ou, pelo menos, de Minas Gerais. Nesse sentido ele escolhe dentro da tradição mineira os temas de sua predileção, de preferência na contramão da mitografia pedagógica estimulada pelo Estado Novo. Em carta ao escritor R. Magalhães Júnior, de 27 de março de 1958, posiciona-se: ” “Nessas histórias da Inconfidência, e outras semelhantes de que se alimenta a História, não sou mitófilo, senão mitófago. E a verdade, talvez, é que eu amo a contradição, inclino-me a olhar o avesso de toda tese.” Para tal empreitada baseia-se na pesquisa escrupulosa dos fatos históricos, alinhando-se a outros revisionistas e nomeando-os com respeito: Capistrano de Abreu, José Veríssimo, Joaquim Norberto, entre outros.

Ao trabalho de pesquisar a história e a literatura mineiras Frieiro agregou o gosto e o talento de bibliógrafo. “Agradeço-lhe muito sensibilizado as amáveis palavras que me escreveu a propósito de $O$ diabo na livraria do cônego. Esse pequeno trabalho é um simples 
divertimento bibliográfico”, escreve, ao acadêmico mineiro Martins de Oliveira, em carta sem data.

Não obstante a (falsa?) modéstia, sua correspondência dá conta da importante assessoria que ele prestou, através de pesquisa bibliográfica, a estudiosos do porte de Rodrigues Lapa, Otto Maria Carpeaux e Brito Broca e Curt Lange, entre outros. A Rodrigues Lapa, que lhe solicita fontes bibliográficas para uma pesquisa sobre as "Cartas Chilenas" responde solícito, em carta de 10 de janeiro de 1939: “Três capítulos da obra de [Alberto] Faria são de interesse para os estudiosos da vida e da obra de Gonzaga: "Criptônimos das Cartas Chilenas”, “Primos de Gonzaga” e “Tropologia das Cartas Chilenas”. A Carpeaux, em carta sem data, escreve: “(...) Por falar em bibliografia mineira (a que alude em sua carta) informo-o de que tenho cerca de 700 fichas e folhetos impressos em tipografias de Minas. Nesse particular, posso gabar-me de ter a melhor (...) bibliografia ...” Com Brito Broca, historiador da literatura brasileira, Frieiro manteve uma correspondência de 1939 a 1959, sempre provendo o amigo de fontes mineiras. Do mesmo modo, o musicólogo Curt Lange muito se beneficiou dos conhecimentos de Frieiro nas sua pesquisas sobre a música mineira do século 18.

Assim é que, do Brasil e de fora pesquisadores de história e literatura brasileiras reportam-se a ele em busca de informações dificilmente encontráveis, aos quais ele responde com presteza e genuína vontade de se aprofundar nos assuntos de Minas. Ao historiador Hélio Silva revela, em carta de 24 de agosto de 1945:

\footnotetext{
Anos há, alimentei o vago projeto de empreender uma obra sobre a produção literária mineira, obra menos crítica do que propriamente bio-bibliográfica. Desisti, por falta de elementos. As obras publicadas na província, em regra, não se encontram nas bibliotecas públicas e, ademais, em Minas não existe uma só grande biblioteca desta espécie. Essas obras, na maioria modestamente impressas, e de pequeninas tiragens, dispersam-se em mãos de particulares.
}

Dentre algumas tentativas de traçar o perfil deste intelectual mineiro, feitas por contemporâneos seus, faz-lhe justiça o ensaísta Fábio Lucas ao afirmar, certa vez, que sua vida se pautou por três paixões: a língua, os livros, as coisas de Minas.

Finalizando, é preciso lembrar que esse escritor envergonhado, como ele próprio se autodenominava, nunca se decidiu a seguir o fluxo da diáspora mineira rumo ao Rio de Janeiro, embora pensasse que na Capital Federal, e somente lá, estava o público do escritor de talento. Recusou, do mesmo modo, inúmeros convites para publicar seus livros em editoras do Rio e de São Paulo embora repetisse, reiteradamente, que "na 
província não há salvação literária”. ${ }^{12}$ São posturas intrigantes que marcaram a sua carreira e suscitam curiosidade sobre essa personalidade de homem tímido e dado ao exercício da autoanálise. Sua extensa correspondência ativa e passiva, aguarda, o interesse de outros biógrafos.

E outro não foi o nosso intento, colocando em cena a figura desse intelectual polígrafo, como se dizia no seu tempo, senão animar outros pesquisadores à reavaliação do seu lugar na história cultural brasileira.

\begin{abstract}
This paper is a profile of the writer Eduardo Frieiro (1889-1982), who was an introvert, prone to self-analysis. He built his self-image in the correspondence he had with intellectuals of his time. The analysis of the corpus of 652 letters makes it possible to identify the construction of a fragmented self-portrait that the researcher redraws as a biographical essay.
\end{abstract}

\title{
KEYWORDS
}

Eduardo Frieiro, correspondence, construction of self-portrait, biography

\section{REFERÊNCIAS}

ÁVILA, Affonso. Um compromisso maior com a liberdade de espírito. Estado de Minas, Belo Horizonte, 25 mar. 1982. Caderno 2, p. 1.

CALLIGARIS, Contardo. Verdades de autobiografias e diários íntimos. Estudos Históricos, Rio de Janeiro, v. 11, n. 21, p. 43-57, 1998.

CARVALHO, M. C. Cordialmente, Eduardo Frieiro: fragmentos (auto)biográficos. Belo Horizonte: Faculdade de Letras/UFMG, 2008.

FOUCAULT, Michel. L’écriture de soi. Corps Écrit, n. 5, p. 3-23, 1983.

FRIEIRO, Eduardo. O clube dos grafômanos. Belo Horizonte: Pindorama, 1927.

\footnotetext{
${ }^{12}$ A mesma ideia é repetida em diversos momentos de sua correspondência ativa. Ficamos aqui com dois exemplos. Ao intelectual argentino Benjamin de Garay escreve em 19 de maio de 1937: "O homo litterarius aqui por estes cafundós, vive como um Robinson. Por mais que faça sinais ninguém lhe dá atenção. $O$ escritor provinciano não chega até o Rio de janeiro, e fora do Rio de Janeiro não há, no Brasil, salvação literária.” E ao espanhol Bráulio SanchezSáez escreve, em 11 de fevereiro de 1945: "De dois anos a esta parte nada tenho escrito, absolutamente nada, nem para a imprensa, nem para o rádio, nem para o livro. Só tenho produzido consumo. Isto é, leio unicamente. (...) Para que escrever? Para nada. Na província não vale a pena. Não dá gosto nem proveito.”
} 
FRIEIRO, Eduardo. A ilusão literária. Belo Horizonte: Os Amigos do Livro, 1932.

FRIEIRO, Eduardo. Um Robinson Literário. In: CAVALHEIRO, Edgard (Org.). Testemunho de uma geração. Porto Alegre: Globo, 1944. p. 15-24.

FRIEIRO, Eduardo. O diabo na livraria do cônego. Belo Horizonte: Cultura Brasileira, 1945.

FRIEIRO, Eduardo. Como era Gonzaga? Belo Horizonte: Secretaria da Educação, 1950.

FRIEIRO, Eduardo. Feijão, angu e couve; ensaio sobre a comida dos mineiros. Belo Horizonte: Centro de Estudos Mineiros, 1966.

FRIEIRO, Eduardo. Novo diário. Belo Horizonte: Itatiaia, 1986.

FRIEIRO, Eduardo. Cartas enviadas. Organização e notas por Maria da Conceição Carvalho. (Não publicado).

LEÃO, Ângela Vaz; CARVALHO, M. C. Conversando sobre Eduardo Frieiro com a professora Ângela Vaz Leão. Rev. Centro de Estudos Portugueses, Belo Horizonte, v. 28, n. 39, p. 243-53, jan./jun. 2008.

LEJEUNE, Phillipe. Le pacte autobiographique. Paris: Seuil, 1975.

LUCAS, Fábio. Mineiranças. Belo Horizonte: Oficina de Livros, 1991.

MOREIRA, Vivaldi. Glossário das Gerais. Belo Horizonte: Imprensa Oficial, 1991.

STAROBINSKI, Jean. Le style de l'autobiographie. Poetique, n. 3, 1970.

TREBITSCH, Michel. Correspondences d'intellectuels, 1992. Disponível em: <http://www.ihtp.cnrs.fr/Trebitsch/cahiers_20html>. Acesso em: 28 jul. 2006.

VIEIRA, Ana Soledad. Eduardo Frieiro; bibliografia. Belo Horizonte: Escola de Biblioteconomia, 1967. Inédito. 